\title{
Farmers Perceived Effectiveness of Information and Communication Technology (ICT) Tools in Karnataka, India
}

\author{
Manjuprakash $^{1^{*}}$, H. Philip ${ }^{2}$ and N. Sriram ${ }^{3}$ \\ ${ }^{1}$ Department of Agricultural Extension, University of Agricultural Sciences, \\ Bangalore - 560065, India \\ ${ }^{2}$ Director of Extension Education, Tamil Nadu Agricultural University, Coimbatore, India \\ ${ }^{3}$ Department of Agricultural extension and Rural Sociology, \\ TamilNadu Agricultural University, Coimbatore, India \\ *Corresponding author
}

\begin{abstract}
A B S T R A C T
Keywords

Farming community, ICT,

Perceived

effectiveness and

multistage random

sampling

Article Info

Accepted:

26 May 2020

Available Online:

10 June 2020

There have been number of ICT initiatives implemented by central, various state governments and private sectors for the benefit of the farming community. An effort was made in 2017 to analyse the perceived effectiveness of ICT tools among the farmers in Koppal district of Karnataka state. Two villages from all the four blocks of the district were selected. From each revenue villages 15 farmer respondents were selected by employing multistage random sampling method which constituted total of 120 respondents. Majority $(86.80 \%)$ of the respondents had medium level of perceived effectiveness of ICT tools in agriculture, followed by 9.10 per cent of the respondents had low level of perceived effectiveness of ICT tools in agriculture. Very meagre $(3.30 \%)$ portion of the respondents had high level of perceived effectiveness of ICT tools in agriculture. In particular over whelming majority $(96.70 \%)$ of the respondents perceived that ICT tools reduce the cost of transportation in acquiring information. Vast majority $(95.80 \%)$ of the respondents quoted that ICT tools help to store and retrieve information any number of times.
\end{abstract}

\section{Introduction}

In this ICT era, the conversation with one another has become so easy by just clicking a button and further the ICT can be best utilised for the transfer of technologies to the farming community in this background there have been number of ICT programmes and projects have been implemented by government and private sector to enable farmers to have access to the relevant information at a right time for the promotion of productivity among various crops. Positive and favourable attitude towards use of ICT is necessary to have positive perceived effectiveness of ICT in agriculture among the farmers. Awareness and knowledge of farmers about the existing ICT projects and services and their relevance 
in agriculture are important factors that lead to positive perceived effectiveness of ICT among farmers in agriculture. The ICT helped fishers along the coastline in Kerala, India learnt about prices at different locations and decided where to sell their products profitably. As a result, price volatility and variation dropped; producer prices rose and at the same time consumer prices dropped was reported by Jensen (2007). Viswanathan (2011) mentioned in his study that the rewards were huge if the economic growth is developed as national infrastructure. Further he stated that for every ten percentage of incremental perception of ICT there is almost 1 to 1.50 per cent growth in GDP. Adawale and Ganiyu (2013) inferred that production activity $(68.30 \%)$, and marketing (47.60 \%) respectively benefited mostly from the use of ICTs by the yam farmers.

\section{Materials and Methods}

The study was conducted in Koppal district of Karnataka state during 2017. The total of all four blocks of the district were selected for the study, as ICT initiatives were tested in the present area which is conducive for the proposed study. Two revenue villages from each of the four selected blocks were considered at random. Further, 15 farmers from each of the selected revenue villages were considered for the survey using simple random technique thus in total 120 respondents were selected from all the blocks by employing multistage random sampling method. A teacher made 22 items were developed covering different opinions on ICT enabled extension services by Government and SAUs in consultation with scientists of Tamil Nadu Agricultural University, Krishi Vigyan Kendra, Gangavathi and extension personnel of State Department of Agriculture, Government of Karnataka. Thus the perception test was developed and validated to measure the perception level of the farmers. The data was collected by using the well-structured and pre-tested interview schedule and appropriate statistical tools were used to analyse the data.

\section{Results and Discussion}

\section{Perceived effectiveness of ICT tools in agriculture}

Perceived effectiveness of ICT tools in agriculture is one of the objectives of the study, this objective is to study the perception of the farming community on use of ICT tools in farming, the various statements consisting of 22 were posed to assess the perception and the result is presented in the Table 1 .

From the Table 1, it could be inferred that majority $(86.80 \%)$ of the respondents had medium level of perceived effectiveness of ICT tools in agriculture, followed by 9.10 per cent of the respondents had low level of perceived effectiveness of ICT tools in agriculture. Very meagre $(3.30 \%)$ portion of the respondents had high level of perceived effectiveness of ICT tools in agriculture. This might be due to the reason that majority of the respondents had medium level of accessibility to ICT and half of the respondents understood the importance of internet and use of ICT gadgets in agriculture and among internet utilization, used internet for both agriculture and non -agricultural purpose.

The findings are on par with the results of Senthilkumar (2003), in his study indicated that majority of the respondents were satisfied in handling and using of cyber extension tools used.

From the Table 2, it could be noticed that, over whelming majority $(96.70 \%)$ of the respondents perceived that ICT tools reduce the cost of transportation in acquiring information. This may be because of the 
reason that the respondents wanted to effectively use their time as they were busy in farm activities and they did not want to spend money for transportation unnecessarily when everything can be checked using ICT gadgets through internet.

Vast majority $(95.80 \%)$ of the respondents quoted that ICT tools help to store and retrieve information any number of times, this might be due to their frequent seeking of the same information and moreover it is the characteristics of ICT gadgets that have an ability to store and furnish the same information any number of times of request hence, it was easy for storage and retrieval of information irrespective of their location.

The majority $(95.00 \%)$ of the respondents felt that ICT helps in knowledge up gradation as they have high exposure to updated or latest technologies in agriculture and allied subject. An ICT tool does not follow two step model of communication theory, which provides equal importance and opportunities for every farmer in acquiring information. Along with this, ICT provides an opportunity for everyone to share their views and correct if the message uploaded found wrong hence, the knowledge acquired will be the accurate and correct one. This may be the reason that the respondents felt that ICT helps in knowledge upgradation.

Majority of the respondents and more precisely 93.30 per cent of them opined that ICT are responsible for easy access of market information and saves human energy. Market information through ICT provides market intelligence with wide coverage of area to analyse the market demand and supply that helps in decision making to make farming profitable with the help of many governmental and non-governmental organisations such as AGMARKNET which provides information to the farmers with respect of all the aspect of the market issues such as demand, supply and the market locations. Similarly same $(93.30 \quad \%)$ proportion of the respondents experienced that ICT tools are too dynamic in nature. This may be because of the constant updation of latest content, information services in accordance with changing scenario. Hence, the respondents felt that ICT tools are too dynamic in nature.

More or less equal (91.70\%) proportion of the respondents fingered out that ICT tools were not efficient everywhere. These are largely due to the poor connectivity of internet in many of the villages and as the tools are highly sophisticated. It needs to be smooth handled and here it is not suitable for persons in midst of farming activities.

ICT tools provide information in time was opined by majority $(90.80 \%)$ of the respondents. They accessed of the information through ICT even when the farmers couldn't contact the extension officials, hence this might be the reason indicated that ICT tools provide information in time.

Farmers retrieved good amount of information whenever need aroused on the spot and 90.00 per cent of the respondents went through that ICT tools hinder of two way communication, this was mainly because of the reason that they couldn't get clarified their doubts which affected the credibility of the content available.

The majority $(87.50 \%)$ of the respondents sensed that ICT provide accurate information as the ICT tools makes searching and retrieval of information more easy. ICT has ocean of data among which the data retrieval is a highly impossible but the technology makes it simple for farmers to retrieve just the data in need with high precision through various 
means like search terms, keywords and pictures. Hence, majority of them perceived that ICT provide accurate information. Exactly 80.00 per cent of the respondents perceived that, information through ICT is credible, because of their psychological feeling that the content provided through ICT are precise and was developed and validated by scientists which, offer the exact and precise solutions to the problems.

A more than three-fourths $(76.70 \%)$ of the respondents felt that use of ICT depicts the status in the society. These were due to the mind-set of the respondents that, the one who used ICT tools have educated and are elite people in the society. Moreover, they are economically sound persons. Hence, possession of ICT tools and ability in accessing ICT tools depicts a higher social status of the farmer.

A three-fourths $(75.80 \%)$ of the respondents believed that ICT helps in capacity building and empowerment, this was largely because of the reason that, usage of ICT needs skills and that will be acquired by practice or by trainings which lead to capacity building and empowerment of the farming community by enabling them to access ICT easily. Less than two-thirds $(60.80 \%)$ of the respondents perceived that ICT tools are easy to operate, the reason behind this may be due to the availability of information in local or regional language. Slightly more than half $(50.80 \%)$ of the respondents perceived that ICT tools are user friendly, ICT tools are costly $(60.00 \%)$ and ICT tools are time consuming $(60.00 \%)$.

More than half $(53.30 \%)$ of the respondents comprehended that ICT are potentials in agricultural sectors. The reason might be due to that government and corporate sectors are in to cyber extension service mode by developing various apps to support agriculture and allied sectors. The enormous growth of ICT renders great support to the farmers in decision making. ICT could also help to manage resources effectively through resource management system. Farmers felt that ICT could be imbibed to implement precision farming successfully through various technologies like GPRS, sensors, remainders, forecast and warnings. Hence, the above results are observed in the study area.

Exactly one-third (33.33\%) of the respondents sensed that ICT tools lack mass appealing, due to dislike of usage of ICT tools and opined that the use of these ICT will waste the time by deviating their time from their routine day to day life. Hence, they felt that, they were not attracted by ICT.

Table.1 Distribution of the respondents according to their Overall Perceived Effectiveness of ICT Tools in Agriculture $(\mathrm{n}=120)$

\begin{tabular}{|c|l|c|c|}
\hline S. No. & Category & Number & Per cent \\
\hline 1. & Low & 11 & 09.10 \\
\hline 2. & Medium & 105 & 86.70 \\
\hline 3. & High & 4 & 03.20 \\
\hline & Total & $\mathbf{1 2 0}$ & $\mathbf{1 0 0 . 0 0}$ \\
\hline
\end{tabular}


Table.2 Itemized Distribution of the respondents according to their Perceived Effectiveness of ICT Tools in Agriculture $(n=120)$

\begin{tabular}{|c|c|c|c|c|c|}
\hline \multirow[t]{2}{*}{ S. No. } & \multirow[t]{2}{*}{ Statements } & \multicolumn{2}{|c|}{ Yes } & \multicolumn{2}{|c|}{ No } \\
\hline & & Number & Per cent & Number & Per cent \\
\hline 1. & ICT tools are user friendly & 61 & 50.80 & 59 & 49.20 \\
\hline 2. & ICT are potentials in agriculture sector & 64 & 53.30 & 56 & 46.70 \\
\hline 3. & ICT tools are easy to operate & 73 & 60.80 & 47 & 39.20 \\
\hline 4. & ICT tools provide information in time & 109 & 90.80 & 11 & 09.20 \\
\hline 5. & They are time consuming (wasting time) & 72 & 60.00 & 48 & 40.00 \\
\hline 6. & $\begin{array}{l}\text { ICT tools help to store and retrieve same } \\
\text { information any number of times }\end{array}$ & 115 & 95.80 & 5 & 04.20 \\
\hline 7. & $\begin{array}{l}\text { ICT tools reduce the cost of transportation } \\
\text { in acquiring information }\end{array}$ & 116 & 96.70 & 4 & 03.30 \\
\hline 8. & $\begin{array}{l}\text { Information through ICT tools are } \\
\text { credible }\end{array}$ & 96 & 80.00 & 24 & 20.00 \\
\hline 9. & Information through ICT are insufficient & 60 & 50.00 & 60 & 50.00 \\
\hline 10. & ICT provide accurate information & 105 & 87.50 & 15 & 12.50 \\
\hline 11. & $\begin{array}{l}\text { ICT are responsible for easy access of } \\
\text { market information }\end{array}$ & 112 & 93.30 & 8 & 06.70 \\
\hline 12. & $\begin{array}{l}\text { ICT tools hinder of two way } \\
\text { communication }\end{array}$ & 108 & 90.00 & 12 & 10.00 \\
\hline 13. & Saves human energy & 112 & 93.30 & 8 & 06.70 \\
\hline 14. & ICT tools are cost effective in nature & 74 & 61.70 & 46 & 38.30 \\
\hline 15. & ICT tools are costly & 72 & 60.00 & 48 & 40.00 \\
\hline 16. & $\begin{array}{l}\text { Use of ICT depicts the status in the } \\
\text { society }\end{array}$ & 92 & 76.70 & 28 & 23.30 \\
\hline 17. & ICT helps in knowledge up gradation & 114 & 95.00 & 6 & 05.00 \\
\hline 18. & Quick dissemination of information & 114 & 95.00 & 6 & 05.00 \\
\hline 19. & Lack mass appealing & 40 & 33.30 & 80 & 66.70 \\
\hline 20. & ICT tools are too dynamic in nature & 112 & 93.30 & 8 & 6.70 \\
\hline 21. & ICT tools are not efficient everywhere & 110 & 91.70 & 10 & 8.30 \\
\hline 22. & $\begin{array}{l}\text { ICT helps in capacity building and } \\
\text { empowerment }\end{array}$ & 91 & 75.80 & 29 & 24.20 \\
\hline
\end{tabular}

Majority $(86.80 \%)$ of the respondents had medium level of Perceived effectiveness of ICT tools in agriculture, followed by 9.10 per cent of the respondents had low level of perceived effectiveness of ICT tools in agriculture. Very meagre $(3.30 \%)$ portion of the respondents had high level of perceived effectiveness of ICT tools in agriculture. Over whelming majority $(96.70 \%)$ of the respondents perceived that ICT tools reduce the cost of transportation in acquiring information.

Vast majority $(95.80 \%)$ of the respondents quoted that ICT tools help to store and retrieve information any number of times, 
majority $(95.00 \%)$ of the respondents felt that ICT helps in knowledge up gradation ICT tools provide information in time was opined by majority $(90.80 \%)$ of the respondents and more than half $(53.30 \%)$ of the respondents comprehended that ICT are potentials in agricultural sectors. Thus there is a need for creating awareness among the farmers and make them feel that the information provided over the ICT are relevant and need to be adopted in the farming and it is also required for training youths in how aspects of utilisation of ICT tools.

\section{References}

Adewale, J. S. and G. O. Adigun. 2013. Use of Information and Communication
Technologies (ICTs) by Yam Farmers in Boluwaduro Local Government Area of Osun State, Nigeria. Library Philosophy and Practice (e-journal).

Jensen, R. 2007. The Digital Provide: Information (Technology) Market Performance and Welfare in the South Indian Fisheries Sector. The Quarterly Journal of Economics, 122(3), 879-924.

Senthil Kumar, M. 2003. Field Testing Cyber Extension Techniques for Transfer of Farm Technology - A Feasibility study. Unpub. Ph.D. Thesis, TNAU, Coimbatore.

Viswanathan, R. 2011. Bringing the ICT to your door steps. Agriculture today. 14(1): 46-47.

\section{How to cite this article:}

Manjuprakash, H. Philip and Sriram, N. 2020. Farmers Perceived Effectiveness of Information and Communication Technology (ICT) Tools in Karnataka, India. Int.J.Curr.Microbiol.App.Sci. 9(06): 3545-3550. doi: https://doi.org/10.20546/ijcmas.2020.906.417 